\title{
Kinetics of Tyrosinase Inhibitory Activity Using Vitis vinifera Leaf Extracts
}

\author{
Yung-Sheng Lin, ${ }^{1}$ Hui-Ju Chen, ${ }^{2}$ Jung-Ping Huang, ${ }^{3}$ Pei-Chi Lee, ${ }^{3}$ Ching-Ru Tsai, ${ }^{3}$ \\ Tzu-Fang Hsu, ${ }^{3}$ and Wen-Ying Huang ${ }^{3}$ \\ ${ }^{1}$ Department of Chemical Engineering, National United University, Miaoli, Taiwan \\ ${ }^{2}$ Department of Food Science and Biotechnology, National Chung Hsing University, Taichung, Taiwan \\ ${ }^{3}$ Department of Applied Cosmetology, Master Program of Cosmetic Science, Hung-Kuang University, Taichung, Taiwan \\ Correspondence should be addressed to Wen-Ying Huang; beca690420@hk.edu.tw
}

Received 20 February 2017; Revised 13 April 2017; Accepted 30 April 2017; Published 1 June 2017

Academic Editor: Mohamed Trigui

Copyright (C) 2017 Yung-Sheng Lin et al. This is an open access article distributed under the Creative Commons Attribution License, which permits unrestricted use, distribution, and reproduction in any medium, provided the original work is properly cited.

\begin{abstract}
Natural medical plant is considered as a good source of tyrosinase inhibitors. Red vine leaf extract (RVLE) can be applied to a wide variety of medical disciplines, such as treatments for chronic venous insufficiency over many decades. This study investigated the tyrosinase inhibitory activity of RVLE containing gallic acid, chlorogenic acid, epicatechin, rutin, and resveratrol which are effective for skin hyperpigmentation. The five components contents are $1.03,0.2,18.55,6.45$, and $0.48 \mathrm{mg} / \mathrm{g}$ for gallic acid, chlorogenic acid, epicatechin, rutin, and resveratrol. The kinetic study showed the tyrosinase inhibitory of RVLE via a competitive reaction mechanism. RVLE solution has an $\mathrm{IC}_{50}$ (the half inhibitory concentration) value of $3.84 \mathrm{mg} / \mathrm{mL}$ for tyrosinase inhibition, that is, an effective tyrosinase inhibitory activity, and can be used as a whitening agent for cosmetic formulations in the future.
\end{abstract}

\section{Introduction}

A wide variety of skin care products, tagged with effective ingredients for skin hyperpigmentation, become the bestselling products in the cosmetics market across Asia [1]. These products containing extracts of plants, like Glycyrrhiza uralensis or Morus alba, usually become popular cosmetics. Numerous studies aimed to search for effective materials for skin hyperpigmentation in an effort to reduce dark spots and hyperpigmentation [2-4]. This inhibitory activity of tyrosinase (EC 1.14.18.1) has been extensively studied over the past years [5-7]. Tyrosinase is the rate limiting enzyme of melanogenesis and the main target of antimelanogenesis [8] and catalyzes the oxidation of L-tyrosine to 3,4dihydroxyphenylalanine (DOPA), which forms dopachrome. These catalyzed reactions result in the formation of melanin, which is responsible for skin pigmentation [9].

Tyrosinase inhibitors can be classified into four types, namely, competitive, uncompetitive, mixed type (competitive/ uncompetitive), and noncompetitive inhibitors. Kojic acid shows a typical competitive inhibitory effect of tyrosinase [10].
Studies on tyrosinase inhibitors, such as hydroquinone, azelaic acid, kojic acid, and arbutin, can effectively expand the scope of research on hypermelanosis [11]. However, there exists certain degree of risk when using a great number of well-known tyrosinase inhibitors. For example, dihydroxybenzene may be irritating, mutagenic, and cytotoxic to sensitive skin, while arbutin and kojic acid may result in contact dermatitis and erythema [12]. Therefore, natural medical plants are considered as a good, and alternative, source of tyrosinase inhibitors. Numerous natural tyrosinase inhibitors are identified and reviewed [13, 14].

A red vine leaf is composed of the dried leaves from cultivars of the plant Vitis vinifera L. [15]. Red vine leaf extract (RVLE) is herbal medicine involving numerous flavonoids as the major active ingredients thereof [16]. It contains not less than $4 \%$ of total polyphenols and $0.2 \%$ of anthocyanins [15]. Numerous investigations reported medical applications of RVLE [17], for example, treatments for chronic venous insufficiency over many decades $[16,18]$. Besides, it could also improve endurance capacity by facilitating fatty acid utilization in skeletal muscle in mice [19]. 
Although RVLE has many pharmacological effects, there is no report on the use of RVLE as a tyrosinase inhibitor. Accordingly, this study aims to investigate the kinetics of tyrosinase inhibitory activity using red vine leaf extracts and to develop an alternative natural cosmetic material.

\section{Materials and Methods}

2.1. Material. Mushroom tyrosinase, chlorogenic acid, epicatechin, schisandrin, and sodium phosphate monobasic were purchased from Sigma-Aldrich (St. Louis, MO, USA). L-3,4-Dihydroxyphenylalanine (L-dopa) and kojic acid were purchased from Acros (New Jersey, USA). Acetonitrile was purchased from Aencore (Surrey Hills, Australia). Sodium phosphate dibasic anhydrous was purchased from J. T. Baker (Petaling Jaya, Selangor, Malaysia). Methanol was purchased from Merck (Darmstadt, Germany). RVLE (Elastvein ${ }^{\circledR}$ ) was purchased from Healthmate (Changhua, Taiwan). Acetic acid was purchased from Panreac (Barcelona, Spain), and gallic acid was purchased from Alfa Aesar (Ward Hill, MA, USA). Rutin was purchased from Extrasynthese (Genay, France). Resveratrol was purchased from TCI (Tokyo, Japan).

2.2. Preparation of RVLE Samples. The solvent used for RVLE preparation was deionized water. Two grams of RVLE was sonicated in an ultrasonic bath (Chrom Tech) for $40 \mathrm{~min}$ with $98 \mathrm{~mL}$ of deionized water. The suspension was centrifuged at $6000 \mathrm{rpm}$ (HERMLE 2206A) for $15 \mathrm{~min}$. The supernatant was collected and run through a $0.45 \mu \mathrm{m}$ filter. One milligram of schisandrin was dissolved in $10 \mathrm{~mL}$ of $70 \%$ methanol and then filtered through a $0.45 \mu \mathrm{m}$ filter. The filtrate was collected as an internal standard solution. Before running the HPLC, $180 \mu \mathrm{L}$ of the RVLE solution was mixed with $10 \mu \mathrm{L}$ of the internal standard solution as a sample solution for analysis [20].

2.3. Calibration and Validation. Five purchased marker standard solutions, $20 \mathrm{mg}$ of gallic acid, $100 \mathrm{mg}$ of chlorogenic acid, $100 \mathrm{mg}$ of epicatechin, $10 \mathrm{mg}$ of rutin, and $10 \mathrm{mg}$ of resveratrol, were individually dissolved with $10 \mathrm{~mL}$ of methanol and stored in a refrigerator for further use. Before adding the internal standard solution, a stock solution was diluted with methanol into a series of standard solutions (gallic acid standard: $60,30,15,7.5$, and $5 \mu \mathrm{g} / \mathrm{mL}$; chlorogenic acid standard: $8.57,6,4.29,3.53$, and $3 \mu \mathrm{g} / \mathrm{mL}$; epicatechin standard: $750,375,187.5,93.75$, and $62.5 \mu \mathrm{g} / \mathrm{mL}$; rutin standard: $100,50,33.33,25$, and $20 \mu \mathrm{g} / \mathrm{mL}$; resveratrol standard: $15,7.5$, $3.75,1.875$, and $1.25 \mu \mathrm{g} / \mathrm{mL}$ ). Each solution was analysed twice by HPLC. Peak areas were plotted versus concentrations to establish a calibration curve of each standard. The recovery was determined by comparing the amount of the marker standard added with that of the marker standard found. The detection limit was determined by a signal to noise $(\mathrm{S} / \mathrm{N})$ ratio of at least $3: 1$. Relative standard derivation (RSD) for reproducibility derived from the variation of the peak-area ratio or retention time in six replicate samples [21].

2.4. HPLC Analysis. An HPLC system (Agilent 1200 Infinity Series, Agilent, USA) is equipped with a quaternary pump, an autosampler, a vacuum degasser, and a diode array detector. A reverse phase column (Cosmosil 5C18-AR II, $5 \mu \mathrm{m}$, $25 \mathrm{~cm} \times 4.6 \mathrm{~mm}$ ID, Nacalai Tesque, Kyoto, Japan) was used. The mobile phase was a mixture of (A) $0.5 \%$ acetic acid and (B) methanol/acetonitrile (2/1, v/v). The mobile phase composition was as follows: $0 \mathrm{~min}, 90 \%$ of (A); 0-10 $\mathrm{min}, 80 \%$ of $(A) ; 10-20 \mathrm{~min}, 60 \%$ of $(A) ; 20-30 \mathrm{~min}, 40 \%$ of $(\mathrm{A})$; and $30-40 \mathrm{~min}, 0 \%$ of $(\mathrm{A})$. The flow rate was $0.8 \mathrm{~mL} / \mathrm{min}$, and the wavelength of the detector was set at $280 \mathrm{~nm}$ [21].

2.5. Analysis of Tyrosinase Inhibitory Activity. Put $40 \mu \mathrm{L}$ of RVLE solution $(3 \mathrm{mg} / \mathrm{mL})$ in a 96 -well plate. Then add $40 \mu \mathrm{L}$ of tyrosinase solutions $(0.693(2.5 \mathrm{U} / \mathrm{mL}), 1.386(5 \mathrm{U} / \mathrm{mL})$, $2.772(10 \mathrm{U} / \mathrm{mL}), 5.544(20 \mathrm{U} / \mathrm{mL}), 6.93(25 \mathrm{U} / \mathrm{mL})$, and 11.088 $(40 \mathrm{U} / \mathrm{mL}) \mu \mathrm{g} / \mathrm{mL}$, resp.) in a sodium phosphate buffer at $\mathrm{pH}$ 6.8 (PBS) and $120 \mu \mathrm{L}$ of the $0.625 \mathrm{mM}$ of L-dopa solution (dissolved in PBS). Put another $40 \mu \mathrm{L}$ of RVLE solution (2, $3,4,5$, and $6 \mathrm{mg} / \mathrm{mL}$ ) in a 96 -well plate. Then add $40 \mu \mathrm{L}$ of tyrosinase solution $(6.93 \mu \mathrm{g} / \mathrm{mL})$ and $120 \mu \mathrm{L}$ of $0.625 \mathrm{mM}$ of L-dopa solution. These mixed solutions were kept at $37^{\circ} \mathrm{C}$ for $30 \mathrm{~min}$ to find the suitable concentrations of tyrosinase used for the tyrosinase inhibitory activity of RVLE. The absorbance was measured at $475 \mathrm{~nm}$ [22] using a Microplate-Reader (Sunrise Basic, Grödig, Austria). Kojic acid (0.01, 0.02, 0.04, 0.06 , and $0.08 \mathrm{mg} / \mathrm{mL}$ ) was used as a positive control, and the solvent control used as a blank was deionized water. The tyrosine inhibition (\%) was calculated by

$$
\text { The inhibition rate }(\%)=\left(1-\frac{\Delta \mathrm{OD}_{\text {sample }}}{\Delta \mathrm{OD}_{\text {control }}}\right) \times 100 \% \text {, }
$$

where $\Delta \mathrm{OD}_{\text {sample }}$ and $\Delta \mathrm{OD}_{\text {control }}$ represent the absorbance of the sample and the control measured at $475 \mathrm{~nm}$, respectively. An $\mathrm{IC}_{50}$ (the half inhibitory concentration) value was determined by regression of a dose-response curve at which $50 \%$ target activity was lost.

2.6. Kinetic Properties of RVLE. A Lineweaver-Burk plot was made by plotting the inverse numbers of the reaction rate $V$ and the concentration of substrate $[\mathrm{S}]$ :

$$
\frac{1}{V}=\frac{K_{m}}{V_{\max }} \times \frac{1}{[S]}+\frac{1}{V_{\max }} .
$$

A linear regression model created in a double reciprocal plot can be used to determine the Michaelis constant $K_{m}$ and the maximum velocity $V_{\max }$, for the reason that the curves therein have the $x$-intercept $1 / K_{m}$, the $y$-intercept $1 / V_{\max }$, and the slope of $K_{m} / V_{\text {max }}$. In addition, a Lineweaver-Burk plot can be used to rate the performance of an inhibitor as competitive, noncompetitive, or even uncompetitive [23].

Before the kinetic studies, the dose-dependent relationship between RVLE and tyrosinase was checked first. Put $40 \mu \mathrm{L}$ of RVLE solution $(0.1875,0.375,0.75,1.5$, and $3 \mathrm{mg} / \mathrm{mL})$ in a $96-$-well plate. Then add $40 \mu \mathrm{L}$ of tyrosinase solutions $(0.693,1.386,2.772,5.544$, and $11.088 \mu \mathrm{g} / \mathrm{mL})$. The substrate was L-dopa by $120 \mu \mathrm{L} 0.1 \mathrm{mM}$ in a sodium phosphate buffer at $\mathrm{pH} 6.8$.

For kinetic studies, another $40 \mu \mathrm{L}$ of RVLE solution ( 0 , $0.375,0.75,1.5$, and $3 \mathrm{mg} / \mathrm{mL}$ ) was put in a 96 -well plate, and 


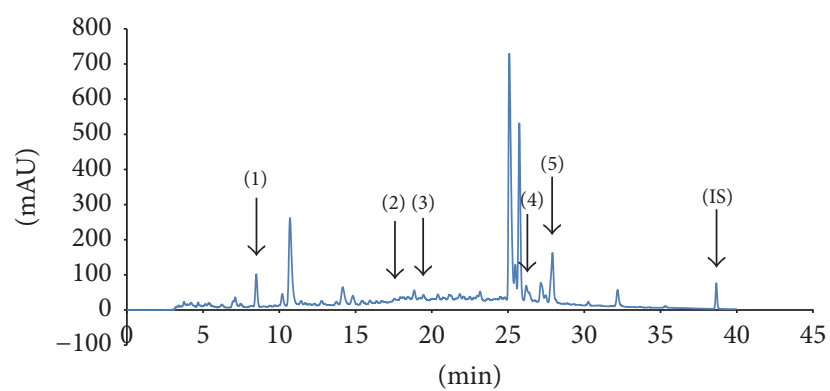

FIGURE 1: HPLC chromatograms of RVLE solution: (1) gallic acid, (2) chlorogenic acid, (3) epicatechin, (4) rutin, and (5) resveratrol and (IS) schisandrin.

then $40 \mu \mathrm{L}$ of tyrosinase solutions $(2.772 \mu \mathrm{g} / \mathrm{mL})$ was added. The substrate was L-dopa solution which was made by $120 \mu \mathrm{L}$ of dissolving L-dopa $(0.078,0.1,0.156,0.3125$, and $0.625 \mathrm{mM}$, resp.) in a sodium phosphate buffer at $\mathrm{pH}$ 6.8. A LineweaverBurk plot was made by plotting the inverse numbers of the reaction rate $(V)$ and the concentration of L-dopa (2) [23].

2.7. Statistical Analysis. Statistical evaluation was performed by running one-way analysis of variance (ANOVA) with SASR software (version 6.08, SAS Institute Inc., Cary, NC, USA). All data were presented as means and standard deviations (mean (SD)). Differences were considered statistically significant in case of a $p$ value less than 0.05 .

\section{Results and Discussion}

3.1. HPLC Analysis. Figure 1 shows the representative HPLC chromatograms of RVLE solution. The bioactive components of RVLE solution are gallic acid, chlorogenic acid, epicatechin, rutin, and resveratrol, which were effective compounds for skin hyperpigmentation confirmed by previous studies [24-27]. These components were identified by a comparison of HPLC chromatograms with standards. Based on the chromatographic analysis results, the five components contents are $1.03,0.2,18.55,6.45$, and $0.48 \mathrm{mg} / \mathrm{g}$ for gallic acid, chlorogenic acid, epicatechin, rutin, and resveratrol, respectively.

3.2. Inhibitory Ability of RVLE Solution. Figure 2 shows the inhibition of tyrosinase activity using RVLE solution as an inhibitor. RVLE solution reduced the tyrosinase activity in a dose-dependent manner. The linear regression line has a slope of 12.216 and $y$-intercept of 3.0097. The $\mathrm{IC}_{50}$ value of RVLE solution was evaluated as $3.84 \mathrm{mg} / \mathrm{mL}$. For comparison, kojic acid was used as a positive control in this study. As in Figure 3, the inhibition of tyrosinase activity increased with the added amount of kojic acid, and its $\mathrm{IC}_{50}$ was $0.014 \mathrm{mg} / \mathrm{mL}$. The tyrosinase inhibitory activity of Vitis vinifera L. was reported in the previous study using the extract of dried stems of the grape tree [28]. Although RVLE solution does not outperform kojic acid as an inhibitor, it was still generally recognized as a safe natural ingredient and could be safely used in cosmetic products [29].

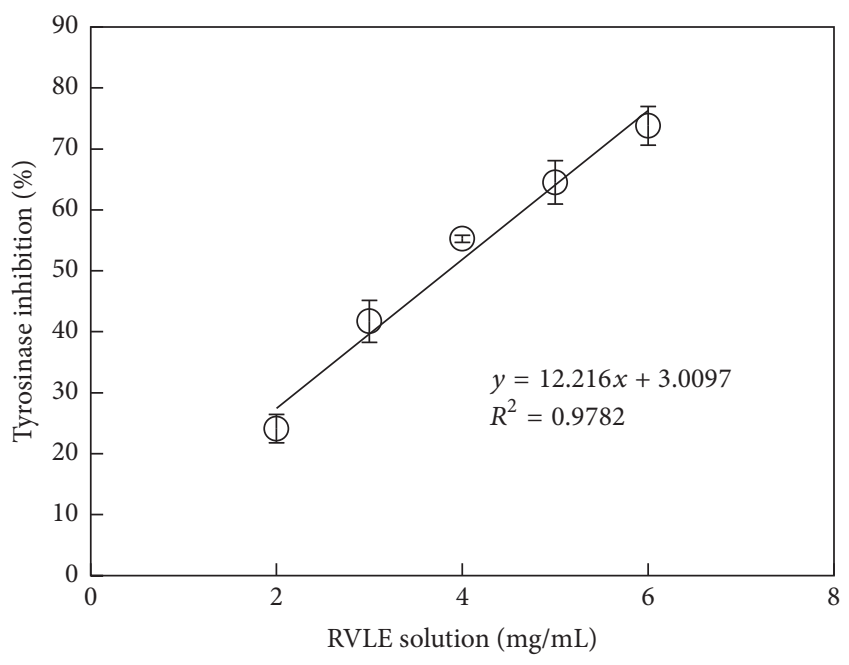

FIGURE 2: Inhibition of the tyrosinase activity using RVLE solution as an inhibitor $(40 \mu \mathrm{L}$ of tyrosinase solution $(6.93 \mu \mathrm{g} / \mathrm{mL})$ and $120 \mu \mathrm{L}$ of $0.625 \mathrm{mM}$ of L-dopa solution were added for each measurement).

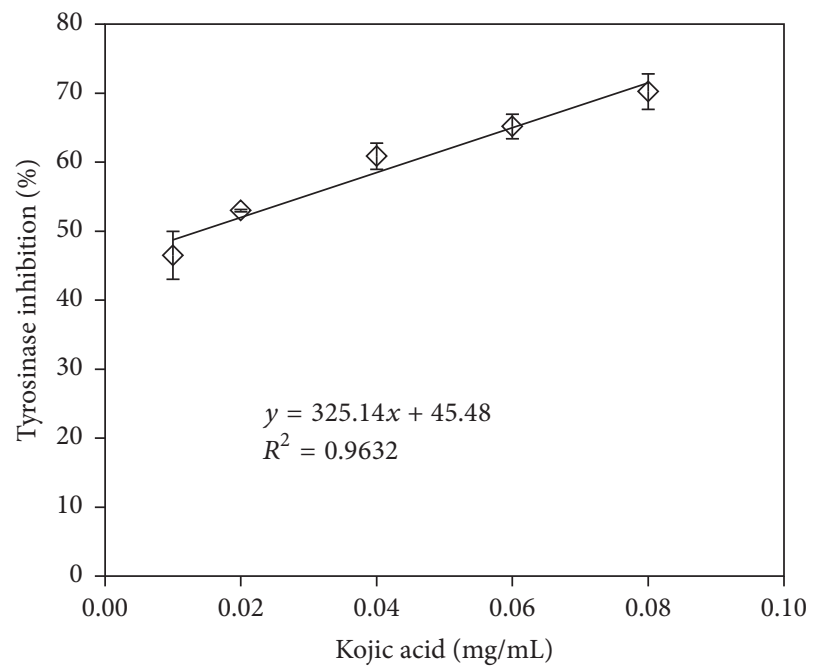

FIGURE 3: Inhibition of the tyrosinase activity using kojic acid as an inhibitor.

3.3. Kinetic Study of Tyrosinase Inhibitory Activity. RVLE solution showed the ability to inhibit the formation of dopachrome, which can be detected using a spectrophotometer at a wavelength of $475 \mathrm{~nm}$. With $0.1 \mathrm{mM}$ of L-dopa as a substrate, tyrosinase activity increased with the added amount of tyrosinase. As illustrated in Figure 4, there exists a linear relationship between the tyrosinase activity and the tyrosinase concentration, while the tyrosinase activity decreases with the added amount of RVLE solution. The RVLE solution is hence validated to inhibit tyrosinase activity successfully. In addition, low slope curves were seen as the amount of RVLE solution increased.

The inhibitory mechanism of RVLE could be further investigated by means of this kinetic study. Figure 5 shows a Lineweaver-Burk double reciprocal plot with the concentration of RVLE solution as a parameter. With L-dopa as 


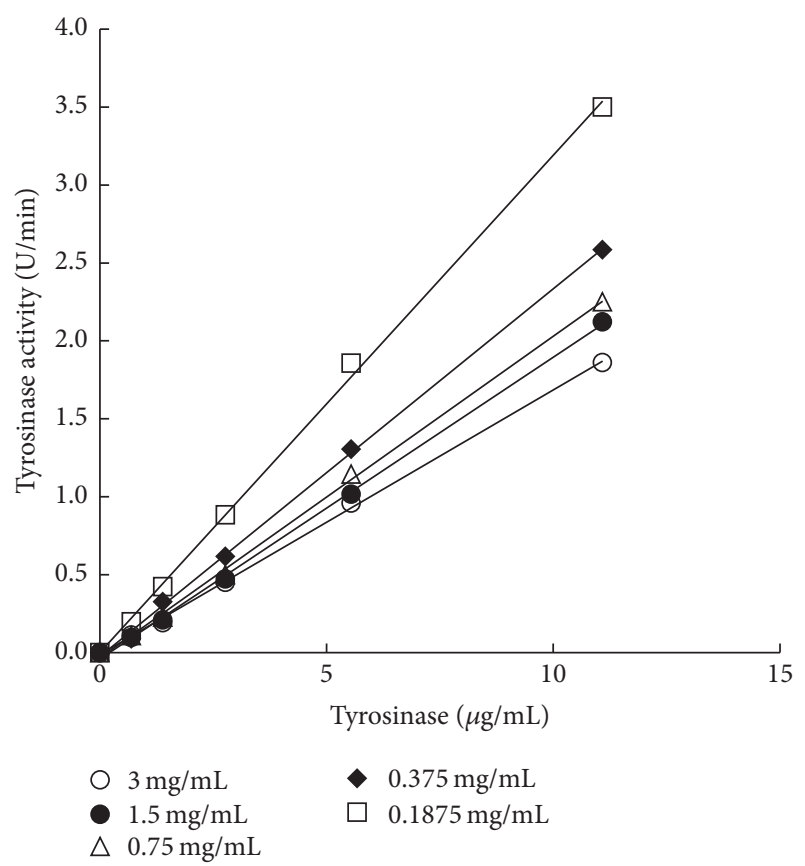

FIGURE 4: Influence of the RVLE concentration on the tyrosinase activity with $0.1 \mathrm{mM}$ of L-dopa as a substrate.

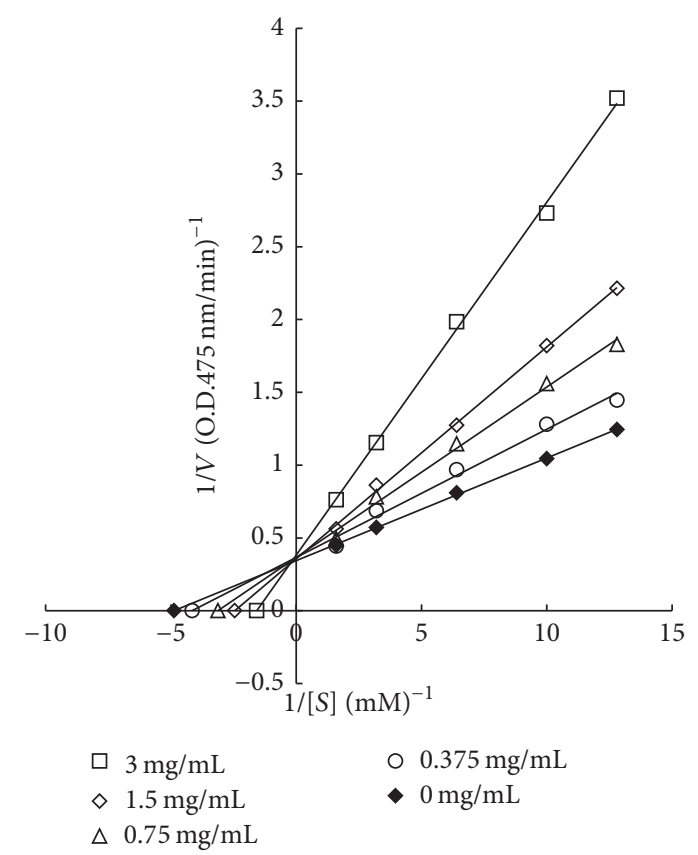

FIGURE 5: Lineweaver-Burk double reciprocal plot of RVLE solution with the concentration as a parameter $(V$ : absorbance change rate, $\Delta \mathrm{OD}_{475 \mathrm{~nm}} / \mathrm{min}$; $[S]$ : concentration of L-dopa).

a substrate, the curves share the same $y$-intercept $1 / V_{\max }$, while the $x$-intercept $-1 / K_{m}$ increased with the concentration of RVLE solution, as illustrated in Figure 5. In other words, $V_{\max }=0.36 \mathrm{mM}$ for all cases, but $K_{m}$ increased due to the introduction of the inhibitor. In this context, the RVLE binding by tyrosinase had an effect on the L-dopa binding.
Therefore, L-dopa and RVLE bound at the same sites on the tyrosinase. According to Figure 5, the inhibitory activity was rated as competitive.

\section{Conclusions}

In this study, it was concluded that a red vine leaf extract (RVLE) solution successfully reduced the tyrosinase activity. It provided an $\mathrm{IC}_{50}$ value of $3.84 \mathrm{mg} / \mathrm{mL}$ for tyrosinase inhibition, and the tyrosinase inhibitory activity was rated as competitive. The bioactive components of RVLE solution contained gallic acid, chlorogenic acid, epicatechin, rutin, and resveratrol. Therefore, RVLE solution could be used in cosmetic formulations as a natural whitening agent.

\section{Conflicts of Interest}

The authors declare no conflicts of interest.

\section{Acknowledgments}

This work was supported by the Ministry of Science and Technology, Taiwan, under Grant no. 105-2622-E-239-001CC3.

\section{References}

[1] C.-F. Chan, C.-C. Huang, M.-Y. Lee, and Y.-S. Lin, "Fermented broth in tyrosinase- and melanogenesis inhibition," Molecules, vol. 19, no. 9, pp. 13122-13135, 2014.

[2] C.-C. Tsai, C.-F. Chan, W.-Y. Huang et al., "Applications of Lactobacillus rhamnosus spent culture supernatant in cosmetic antioxidation, whitening and moisture retention applications," Molecules, vol. 18, no. 11, pp. 14161-14171, 2013.

[3] H.-H. Ko, Y.-C. Chiang, M.-H. Tsai et al., "Eupafolin, a skin whitening flavonoid isolated from Phyla nodiflora, downregulated melanogenesis: Role of MAPK and Akt pathways," Journal of Ethnopharmacology, vol. 151, no. 1, pp. 386-393, 2014.

[4] K. Murata, K. Takahashi, H. Nakamura, K. Itoh, and H. Matsuda, "Search for skin-whitening agent from Prunus plants and the molecular targets in melanogenesis pathway of active compounds," Natural Product Communications, vol. 9, no. 2, pp. 185-188, 2014.

[5] S.-Y. Seo, V. K. Sharma, and N. Sharma, "Mushroom tyrosinase: recent prospects," Journal of Agricultural and Food Chemistry, vol. 51, no. 10, pp. 2837-2853, 2003.

[6] Y.-J. Kim and H. Uyama, "Tyrosinase inhibitors from natural and synthetic sources: Structure, inhibition mechanism and perspective for the future," Cellular and Molecular Life Sciences, vol. 62, no. 15, pp. 1707-1723, 2005.

[7] Z. Yang, Y. Zhang, L. Sun, Y. Wang, X. Gao, and Y. Cheng, "An ultrafiltration high-performance liquid chromatography coupled with diode array detector and mass spectrometry approach for screening and characterising tyrosinase inhibitors from mulberry leaves," Analytica Chimica Acta, vol. 719, pp. 8795, 2012.

[8] J. P. Ebanks, R. R. Wickett, and R. E. Boissy, "Mechanisms regulating skin pigmentation: the rise and fall of complexion coloration," International Journal of Molecular Sciences, vol. 10, no. 9, pp. 4066-4087, 2009. 
[9] T. Fukai, Y. Oku, A.-J. Hou, M. Yonekawa, and S. Terada, "Antimicrobial activity of isoprenoid-substituted xanthones from Cudrania cochinchinensis against vancomycin-resistant enterococci," Phytomedicine, vol. 12, no. 6-7, pp. 510-513, 2005.

[10] T.-S. Chang, "An updated review of tyrosinase inhibitors," International Journal of Molecular Sciences, vol. 10, no. 6, pp. 2440-2475, 2009.

[11] E. C. Davis and V. D. Callender, "Postinflammatory hyperpigmentation: a review of the epidemiology, clinical features, and treatment options in skin of color," Journal of Clinical and Aesthetic Dermatology, vol. 3, no. 7, pp. 20-31, 2010.

[12] C.-Y. Lien, C.-Y. Chen, S.-T. Lai, and C.-F. Chan, "Kinetics of mushroom tyrosinase and melanogenesis inhibition by $\mathrm{N}$ acetyl-pentapeptides," Scientific World Journal, vol. 2014, Article ID 409783, 9 pages, 2014.

[13] T.-S. Chang, "Natural melanogenesis inhibitors acting through the down-regulation of tyrosinase activity," Materials, vol. 5, no. 9, pp. 1661-1685, 2012.

[14] B. Burlando, M. Clericuzio, and L. Cornara, "Moraceae plants with tyrosinase inhibitory activity: a review," Mini-Reviews in Medicinal Chemistry, vol. 17, no. 2, pp. 108-121, 2016.

[15] S. Chrubasik, "Vitis Viniferae Folium (Red vine Leaf)," in Phytotherapy Research, pp. 284-288, 2nd edition, 2009.

[16] H. Kiesewetter, J. Koscielny, U. Kalus et al., "Efficacy of orally administered extract of red vine leaf AS 195 (folia vitis viniferae) in chronic venous insufficiency (stages I-II): a randomized, double-blind, placebo-controlled trial," Arzneimittelforschung, vol. 50, pp. 109-117, 2000.

[17] M. Nassiri-Asl and H. Hosseinzadeh, "Review of the pharmacological effects of Vitis vinifera (grape) and its bioactive compounds," Phytotherapy Research, vol. 23, pp. 1197-1204, 2009.

[18] E. Rabe, M. Stücker, A. Esperester, E. Schäfer, and B. Ottillinger, "Efficacy and tolerability of a red-vine-leaf extract in patients suffering from chronic venous insufficiency - Results of a double-blind placebo-controlled study," European Journal of Vascular and Endovascular Surgery, vol. 41, no. 4, pp. 540-547, 2011.

[19] Y. Minegishi, S. Haramizu, T. Hase, and T. Murase, "Red grape leaf extract improves endurance capacity by facilitating fatty acid utilization in skeletal muscle in mice," European Journal of Applied Physiology, vol. 111, no. 9, pp. 1983-1989, 2011.

[20] W. Y. Huang, P. C. Lee, J. C. Hsu, Y. U. Lin, H. J. Chen, and Y. S. Lin, "Effects of water quality on dissolution of Yerba Mate extract powders," The Scientific World Journal, vol. 2014, Article ID 768742, 6 pages, 2014.

[21] W. C. Liao, Y.-H. Lin, T.-M. Chang, and W.-Y. Huang, "Identification of two licorice species, Glycyrrhiza uralensis and Glycyrrhiza glabra, based on separation and identification of their bioactive components," Food Chemistry, vol. 13, pp. 21882193, 2012.

[22] P. Suganya, K. Jeyaprakash, G. R. Mallavarapu, and R. Murugan, "Comparison of the chemical composition, tyrosinase inhibitory and anti-inflammatory activities of the essential oils of Pogostemon plectranthoides from India," Industrial Crops and Products, vol. 69, pp. 300-307, 2015.

[23] H. Hemachandran, A. Anantharaman, S. Mohan, and etal., "Unraveling the inhibition mechanism of cyanidin-3-sophoroside on polyphenol oxidase and its effect on enzymatic browning of apples," Food Chemistry, vol. 227, pp. 102-110, 2017.
[24] K. N. Jae, Y. S. Do, J. K. You et al., "Inhibition of tyrosinase by green tea components," Life Sciences, vol. 65, no. 21, pp. 241-246, 1999.

[25] P. Bernard and J.-Y. Berthon, "Resveratrol: an original mechanism on tyrosinase inhibition," International Journal of Cosmetic Science, vol. 22, no. 3, pp. 219-226, 2000.

[26] T.-R. Su, J.-J. Lin, C.-C. Tsai et al., "Inhibition of melanogenesis by gallic acid: Possible involvement of the PI3K/Akt, MEK/ERK and Wnt $\beta$-catenin signaling pathways in B16F10 cells," International Journal of Molecular Sciences, vol. 14, no. 10, pp. $20443-$ 20458, 2013.

[27] M. M. de Freitas, P. R. Fontes, P. M. Souza, and etal., "Extracts of Morus nigra L. leaves standardized in chlorogenic acid, rutin and isoquercitrin: tyrosinase inhibition and cytotoxicity," PLOS ONE, vol. 11, no. 9, Article ID e0163130, 2016.

[28] J. Park and Y. C. Boo, "Isolation of resveratrol from vitis viniferae caulis and its potent inhibition of human tyrosinase," Evidence-based Complementary and Alternative Medicine, vol. 2013, Article ID 645257, 11 pages, 2013.

[29] F. Fernandes, E. Ramalhosa, P. Pires et al., "Vitis vinifera leaves towards bioactivity," Industrial Crops and Products, vol. 43, no. 1, pp. 434-440, 2013. 

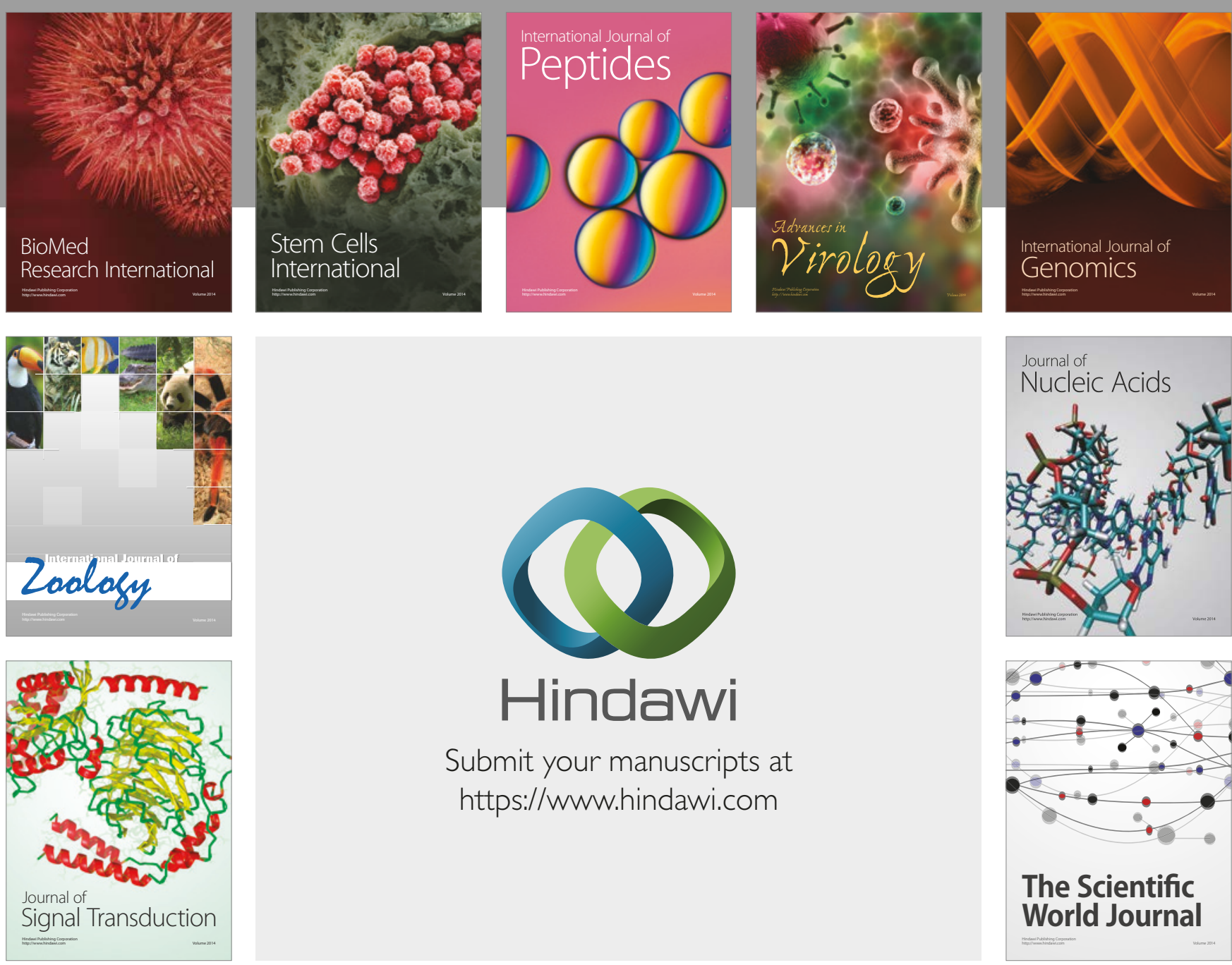

Submit your manuscripts at

https://www.hindawi.com
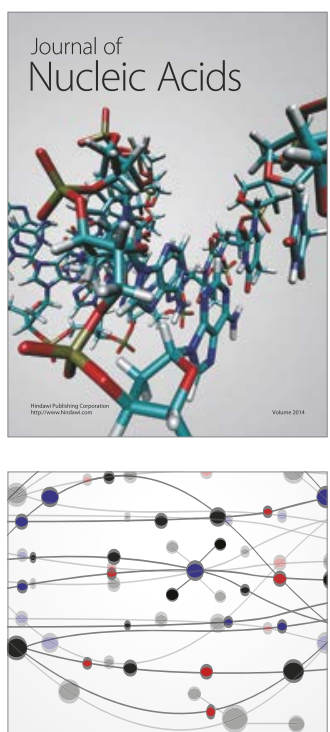

The Scientific World Journal

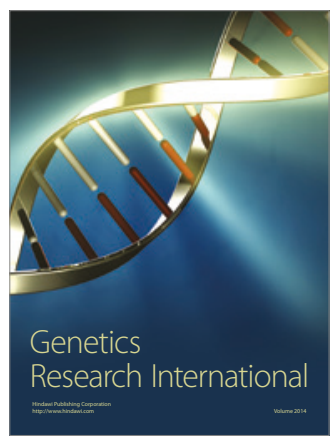

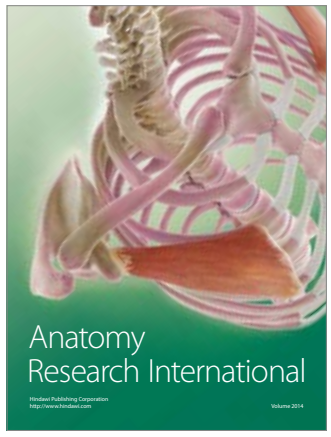

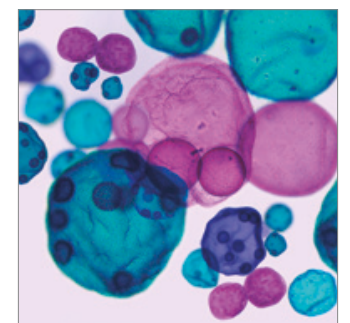

International Journal of Microbiology
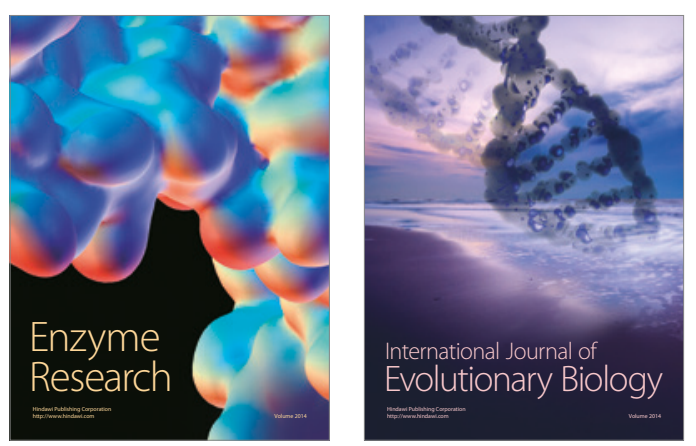
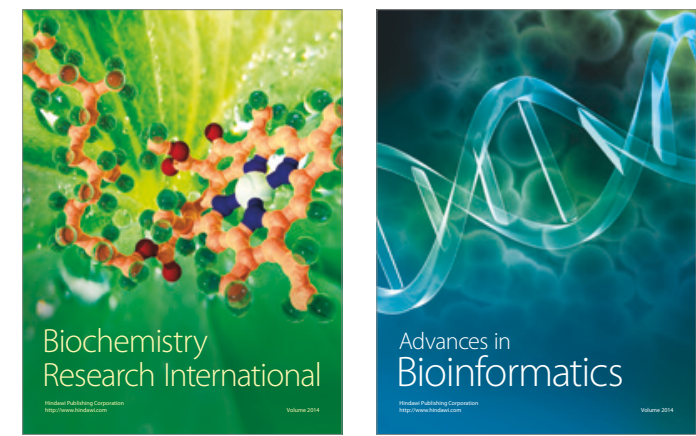

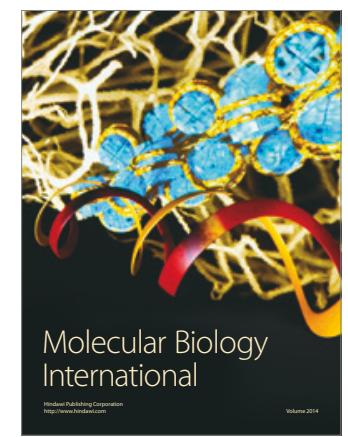

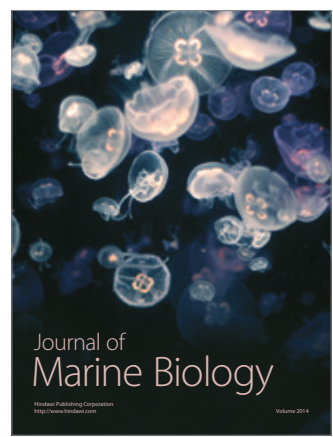

